\title{
Magnesium-Silicate-Hydrate
}

\section{(M-S-H) nucleation in presence of polymeric additives}

\author{
MAXIMILIAN MARSISKE ${ }^{1}$, CRISTINA RUIZ- \\ AGUDO $^{1}$
}

maximilian.marsiske@uni-konstanz.de

1 University of Konstanz, Universitätsstrasse 10

78457 Konstanz (Germany)

With more than 4 billion tons are produced annually cement is one of the most used resources worldwide ${ }^{[1]}$. But cement faces a dilemma. On the one hand, with $5-8 \%$ it is one of the major contributors to anthropogenic greenhouse gas emission but on the other hand, it is amongst the group of low carbon materials ${ }^{[1-2]}$. Most of the carbon dioxide emissions are linked to the processing of its raw materials. In a hightemperature calcination process, limestone $\left(\mathrm{CaCO}_{3}\right)$ is converted to $\mathrm{CaO}$ releasing $\mathrm{CO}_{2}$.

A possible solution to the problem lies in the use of materials with lower environmental impact. In contrast to limestone $\left(\mathrm{CaCO}_{3}\right)$, magnesite $\left(\mathrm{MgCO}_{3}\right)$ can be processed at lower temperatures ${ }^{[3]}$, saving a significant amount of energyyielding in the reduction of $\mathrm{CO}_{2}$ emissions. However, $\mathrm{Mg}$ based cement is only a niche product due to its noncompetitive material properties and high cost ${ }^{[4]}$.

To make Mg-based cement compatible, the approach is to investigate the material from the bottom up - directly speaking from its crystallization. To unravel the crystallization process, titration experiments are conducted to determine in-situ the different stages occuring in the formation of Magnesium-Silicate-Hydrate (M-S-H). Characterization of the final product was done by multiple techniques (TEM, SEM, IR, XRD) that are traditionally used in mineralogy for the analysis of morphology, crystallinity and composition of substances. Additionally, the effect of polymeric additives on M-S-H was tested with the aim to identify promising substances towards fine-tuning the properties of M-S-H cement by controlling the different stages along the crystallization pathway.

\footnotetext{
[1] J. Lehne, F. Preston, Chatham House Report, Energy Enivronment and Resources Department: London, UK 2018, 1-66.

[2] T. Boden, R. Andres, G. Marland, Environmental System Science Data Infrastructure for a Virtual Ecosystem ..., 2017.

[3] J. Zhu, N. Ye, J. Liu, J. Yang, Industrial \& Engineering Chemistry Research 2013, 52, 6430-6437.

[4] S. A. Walling, J. L. Provis, Chemical reviews 2016, 116, 4170-
} 